\title{
Evaluation of Acute Toxicity and Sedative Effects of Ethylic Extract of Thymelaea lythroides in Wistar Rats
}

\author{
Inssaf Berkiks' ${ }^{1}$, Abdelhalem Mesfioui' ${ }^{1}$, Abdrahim Kribii' ${ }^{2}$ Ali Ouichou${ }^{1}$, \\ Bouchra Benazzouz ${ }^{1}$, Aboubaker El Hessni1 \\ ${ }^{1}$ Laboratoire de Génétique, Neuroendocrinologie et Biotechnologie, Faculté des Sciences BP 133, Kenitra, \\ Maroc \\ ${ }^{2}$ Laboratoire de Procédés de Séparation, Equipe de Chimie Appliquée à l’Environnement, Faculté des Sciences, \\ Université Ibn Tofail, Kénitra, Maroc \\ Email: berkiksinssaf@hotmail.com
}

Received 14 January 2014; revised 19 February 2014; accepted 27 February 2014

Copyright @ 2014 by authors and Scientific Research Publishing Inc.

This work is licensed under the Creative Commons Attribution International License (CC BY).

http://creativecommons.org/licenses/by/4.0/

(c) (i) Open Access

\section{Abstract}

The purpose of this study was to evaluate the acute toxicity and sedative effect of the ethylic extract of Thymelaea lythroides (TI) on Wistar rats. The study was based on the gavage administration of the ethylic extract of $T l$ with different doses (i.e. $200,400,500$ and $5000 \mathrm{mg} / \mathrm{kg}$ ), where the toxicity and the sedative activity of the plant were observed and the obtained results were analyzed using the ANOVA test followed by the Bonferroni test. The main results of this study showed that the lethal dose of the ethylic extract of $T l$ was higher than the $5000 \mathrm{mg} / \mathrm{kg} \mathrm{dose}$. Moreover, when compared to the control rats, the animals treated with $5000 \mathrm{mg} / \mathrm{kg}$ of the extract exhibited significant reduction in appetite for food and water in the first week. Furthermore, results of the psychotropic test conducted during this study showed visible effects on the exploratory activity of the rats. The dose of $5000 \mathrm{mg} / \mathrm{kg}$ was also found to have a significant central nervous system effect; the locomotor activities of the animals decreased in a manner similar to those administered with Zepam as control.

\section{Keywords}

T. lythroides; Acute Toxicity; Central Nervous System Effect; Sedative

\section{Introduction}

Thymelaea is a genus comprising about 30 species of evergreen shrubs under the flowering plant family. Thy-

How to cite this paper: Berkiks, I., Mesfioui, A., Kribii, A., Ouichou, A., Benazzouz, B. and El Hessni, A. (2014) Evaluation of Acute Toxicity and Sedative Effects of Ethylic Extract of Thymelaea lythroides in Wistar Rats. Journal of Behavioral and Brain Science, 4, 120-128. http://dx.doi.org/10.4236/jbbs.2014.43016 
melaeaceae, one of these species-which is the main focus in this article-is known as $T l[1]$. $T l$ is a shrub that can be 40 to $70 \mathrm{~cm}$ tall with deep roots and a swivel. Its rods are elongated and upright with many leafy branches over their entire length (or almost the totality of their length) and the foliage is dark green and persistent. Additionally, the leaves of $T l$ are alternate, sessile, oblong-lanceolate and slightly concave, and the older leaves are glabrous below, while they are covered with a whitish tomentum in abundance above, and inflorescences are on top of the twigs with 2 to 9 sessile flowers, where the male and female flowers are distinct, and a small fruit is indehiscent with a single seed [2].

The systematics of the plant is as follows: e.g. Kingdom: Plantae, Phylum: spermatophyte, Under Phylum, Angiosperm, Class: Eudicotylidon, Underclass: Rosadae, Order: Malvales, Family: Thymelaeaceae, Genus: Thymelaea, Species: Thymelaea lythroides [3].

$\mathrm{Tl}$ is native to North Africa, especially in the Kingdom of Morocco where it is commonly known as "Methnane", and according to the research done by Dohou (2004) [4], it has been used traditionally in the treatment of some pains and diseases such as: male bladder or kidney' problems, cold and back pains inflammation of the eyes, swelling, fractures and against rheumatism and inflammation of the prostate. Moreover, the plant is used in the case of infertility in women, as an anti-inflammatory and for the treatment of hypertension [5].

However, toxicities of phytochemical from the family of Thymelaceae have been reported. For example: two of its components (i.e.: diterpenes and tigliane daphnane) are violent purgatives that trigger, by contact with the skin or mucosa, an intense inflammatory reaction [6]. Additionally, preliminary studies carried out in our laboratory showed that the essential oil of $T l$ had a sedative effect. Therefore, the present study was designed to evaluate:

1) the acute toxicity of the ethylic ether extract of $T l$ on "Wistar" rats and the reversibility of its toxic effects.

2) the sedative effect of the ethylic ether extract.

\section{Materials and Methods}

\subsection{The Plant}

T.l was collected from the Maâmora forest, in the Kénitra city located north of the Moroccan capital. Rabat, in late December 2012, and it was dried in the open air. The plant is authentiquâtes by Laboratoire de Botanique et de Protection des Plantes. Faculty of Sciences. Ibn Tofail University. Maroc.

\subsection{Preliminary Phytochemical Screening}

The qualitative chemical investigation of the ethylic ether extract was carried out to check for the presence of various phytoconstituents, and it has revealed the existence of quinones libres, anthraquinones, saponosides, coumarines, flavonoides, tanins, aglycones, terpene sterol and C-heterosides.

\subsection{Extraction Method}

The aerial part of the plant was dried, crushed and macerated by ethylic ether for one week at room temperature, and afterward the extracts were separated from the residues first by sieving through several layers of muslin cloth in order to remove coarse particles, and then filtering through Whatman No. 1 paper. After that, the extract was recovered and concentrated and dried by evaporation in the open area.

\subsection{Animals}

The study was performed on male adults Wistar rats (90 days old) in accordance with the guidelines of both the Organisation for Economic Cooperation and Development (OECD) and the Food and Drug Administration (FDA). At the beginning of the test, the weight of each rat was chosen within a range of $\pm 20 \%$ of the average weight of all the animals used in this study with respect to the principles governing research on animals as defined by the OECD (2000) [7] and the Canadian Council on Animal Care (CCAC) [8]. Then, the animals were grouped and placed into scientific cages located in the animals room, which was maintained at a temperature of $22^{\circ} \mathrm{C}$ to $24^{\circ} \mathrm{C}$ and a humidity between $60 \%$ and $70 \%$, and where the animals had free access to water and food (standard food) The rats were maintained under these conditions for five days in order to acclimatize with the environment. 


\subsection{Acute Toxicity Test}

The acute oral toxicity was conducted on the ethyl residue extracted according to the guidelines of the OECD (2001), male wistar rats weighing 100 to $120 \mathrm{~g}$ were used and were divided into 6 groups comprising 6 animals each including a control group on which no test was performed. Additionally, the animals were not fed overnight before the administration of the test sample but they had free access to water [9].

the extract was administered by gavage using a dose of $200 \mathrm{mg} / \mathrm{kg}$ of dried extract dilued in $1 \mathrm{ml}$ of table oil and the tested group was observed for all toxic symptoms, behavioral changes, locomotion, convulsions and mortality for the duration of 72 hours. However, the ethylic ether extract used in the study showed no signs of toxicity in the first tested group, and therefore, higher doses of 400, 500, 2000 and $5000 \mathrm{mg} / \mathrm{kg}$ were administered to the remaining four groups by single oral administration, and the animals were first observed to check for behavioral changes for 72 hours, and then they were monitored for a period of 14 days in order to look for signs of toxicity and mortality.

The observation of the mortality-after a single administration of the $T l$ plant-will allow us to determine the Minimum Lethal Dose (MLD) and the No Observable Adverse Effects Levels (NOAEL) during the toxicity test period.

\subsection{Clinical Observations}

The test animals were observed for clinical abnormalities twice on the study day 0 (i.e.: the post dose and afterwards on a daily basis (i.e.: from day 1 to day 14), where a general health/mortality check was performed twice a day, in the morning and in the afternoon, and where the body weight, ingestion and temperature were obtained once every day.

\subsection{Psychotropic Tests}

The main objective was to evaluate the sedative effect of the $T l$ extract. Therefore, the tests were realized using the dose(s) lower than the LD50-in order to make use of a dosage that does not cause death-and 5 lots consisting of 5 rats each were used including a lot of control receiving table oil, a reference lot receiving a dose of Zepam $6 \mathrm{mg} / \mathrm{kg}$, and three lots receiving the doses of the ethylic ether extract (i.e.: the 200, $400 \mathrm{and} 500 \mathrm{mg} / \mathrm{kg}$ ). Afterwards, the sedative effects of the ethylic ether extract were verified and outlined by performing the following tests on the groups of rats:

\subsection{Hole Board Test}

To evaluate the effects of psychotropic drugs on a rat's exploration (neophilia) and special learning behavior, the Hole Board Test is frequently used. the Hole-Board apparatus is designed as an enclosed arena with holes in the floor into which an animal can poke its head (i.e. head-dipping); when confronted with a new environment, the natural tendency of a mouse or a rat is to explore any present hole by plunging its head in and out of the hole a few times and then moving on to the next hole. Therefore, the purpose of the Hole-Board test is to assess the effects of psychotropic drugs on the rat's head dipping and to explore its activity, where in general a high frequency of head dipping is reflective of normal neophilia while low levels of head dipping is usually indicative of high anxiety level that prevents the animal from exploring [10].

The frequency and duration of head dipping were recorded to provide a measure of exploration behavior half an hour from the oral treatment with oil table (1 ml/kg), $T l$ (200, 400 and $500 \mathrm{mg} / \mathrm{kg})$ and Zepam $(6 \mathrm{mg} / \mathrm{kg})$, one after the other, each rat from each lot was placed at one corner of the board, and ultimately started moving around and dipping its head into the holes. Then, during each individual test of 5 minutes duration, the number of head dips per minute was recorded for each rat.

\subsection{Open Field Test}

The standard Open Field Test is commonly used to assess locomotors, exploratory and anxiety-like behavior in laboratory animals (e.g. rats and mice). Therefore, this test is particularly useful in evaluating the effects of anxiolytic and anxiogenic drugs, the locomotor responses to drugs and also the behavioral responses to novelty. The Open Field area generally consists of an empty and bright square—or circular—arena, surrounded by walls 
to prevent animal from escaping, and the animal is usually placed in the center of the arena and its behavior is recorded over a chosen period of time (i.e. from 3 to 15 minutes).

The Open Field test task approaches the conflict between the rats' desire to explore new environments versus the innate fear that they have of the central area of a novel or brightly lighted open field; as it is known that when anxious, the natural tendency of rats is to prefer staying closer to the walls (thigmotaxis). Thus, in relation to this study, anxiety-related behavior was measured by evaluating the degree to which the rats avoided the center of the Open Field arena, and immediately after the Hole Board test, the animals were put into test and were placed into the center of the open field area in order to measure the locomotor activity during $10 \mathrm{~min}$ [11].

\subsection{Statistical Analysis}

The results obtained were expressed as mean \pm SEM $(n=5)$. The data were analyzed using oneway ANOVA followed by Bonferroni's post-hoc test. Results were considered significant when $P<0.05$.

\section{Results}

\subsection{Assessment of the Acute Toxicity}

After oral administration of the ethyl extract of $T l$ at different doses, the rats were observed for 14 days, and the rat's mortality was examined for each dose. The results have shown that no mortality was recorded for the administered doses, but they have uncovered signs of toxicity regarding the $5000 \mathrm{mg} / \mathrm{kg}$ dose including symptoms such as: rats disassociation (i.e. the rats were not grouped), little reaction of the rats towards the sonority-driven stress, sneezing, rough hair, hair loss in the area surrounding the eyes and physical illness. Consequently, it could be deduced that the LD50 is a dose that is more than $5000 \mathrm{mg} / \mathrm{kg}$, and that the NOAEL dose is $500 \mathrm{mg} / \mathrm{kg}$, and therefore, the ethylic ether extract of the $T l$ plant was non-toxic to the test animals.

\subsection{Change in Body Weight and Ingestion}

During the experimental period, the weights of the rats were recorded on a daily basis every morning at the same time, and as shown in Figure 1, changes in the body weight of the control lot of rats and the other tested lots were determined and the values starting from day 0 to day 14 were outlined.

The results show that at the beginning of the experiment (i.e.: day 0), all the lots of rats had homogeneous weights ranging from 100 to $120 \mathrm{~g}$. However, during the first four days, the lot administered the $T l$ extract at a dose of $5000 \mathrm{mg} / \mathrm{kg}$ witnessed a constant body weight, which marks a difference when compared to the lot of control and the other tested lots that had an increase in the body weight, and this difference was significant during days 3 and 4 . Additionally, at the end of the $1^{\text {st }}$ week, another significant divergence in the body weights was found-between the lot tested with $5000 \mathrm{mg} / \mathrm{kg}$ on one hand and the control lot and the other tested lots on the other hand—as the lot administered with $5000 \mathrm{mg} / \mathrm{kg}$ experienced an increase in body weight. Nevertheless, during the $2^{\text {nd }}$ week, and despite a slight drop in body weight for the lots administered with 200, 400 and 500 $\mathrm{mg} / \mathrm{kg}$ on day 8 , there was no significant variation between the control lot and other lots and there was just a normal increase in body weight for all the groups (Figure 1).

\subsection{Digestive Ingestion}

The results presented in Figure 2 show that the administration of the ethylic ether extract of the plant does not cause significant changes in the food and water intakes of the experimented rats when compared to the control rats during the first and the second week of observation. However, food consumption in g/day/rat was greatly reduced due to the administration of the $5000 \mathrm{mg} / \mathrm{kg}$ dose and this variation was significant in the first week and not in the second week.

\subsection{Psychotropic Activity}

\subsubsection{Hole Board Test}

The test displays the rats' curiosity in every minute throughout the 5 minutes of test's duration, and the rats' exploration of the holes was evaluated by counting the number of head dips each minute (Figure 3). During the first and second minutes of the hole board test, a decrease in the rats' activities was observed and the variation 


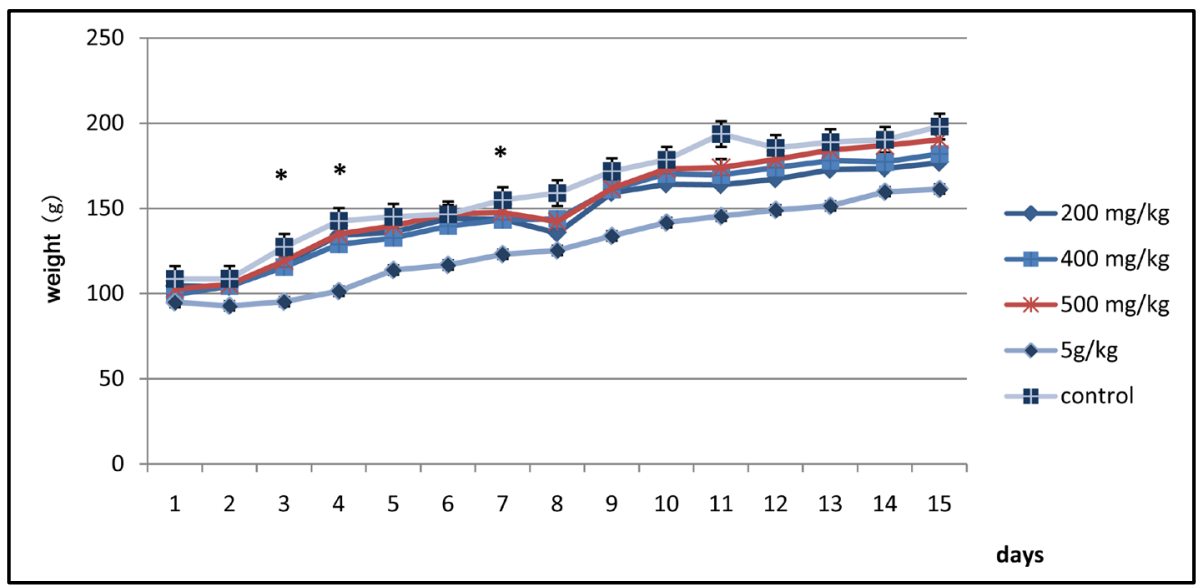

Figure 1. Representation of the changes in the body weight of the control lot and the other tested lots of rats.
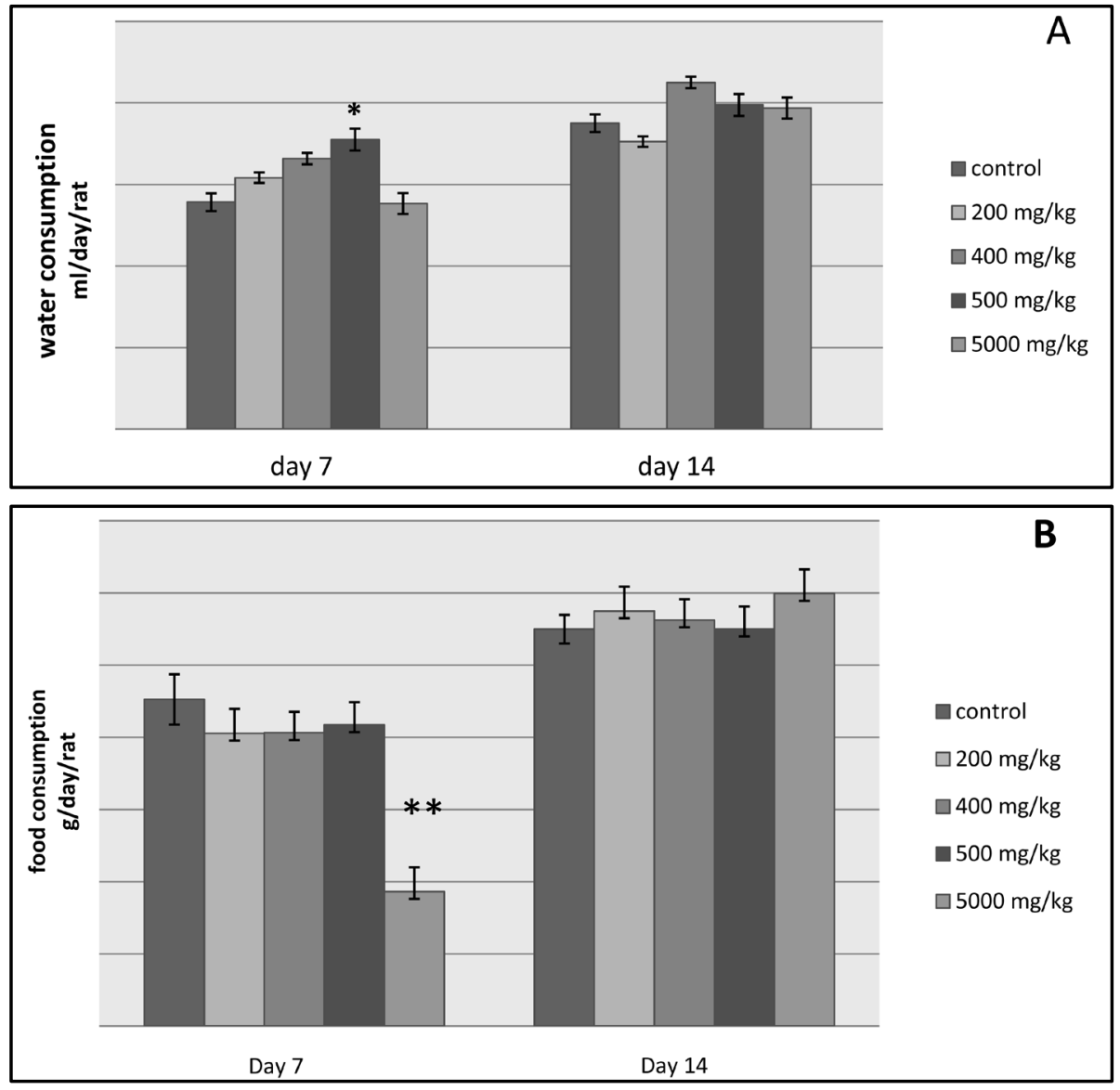

Figure 2. The histograms A and B outline the water and food consumption in g/day/rat respectively of the control lot and the other tested lots of rats.

was not significant between the control lot that has received table oil, the group of rats administered with the different doses of T. lythroides's extract and the lot tested using zepam (i.e.: the reference molecule). However, in the third minute, there is a significant difference between the control lot that had an increase in its activity level and the other lots subject to the test that have experienced a decreased activity level. Additionally, despite the drop in the activity of all the lots expect for the $200 \mathrm{mg} / \mathrm{kg}$ group-as this lot saw an increase in the rats' ex- 


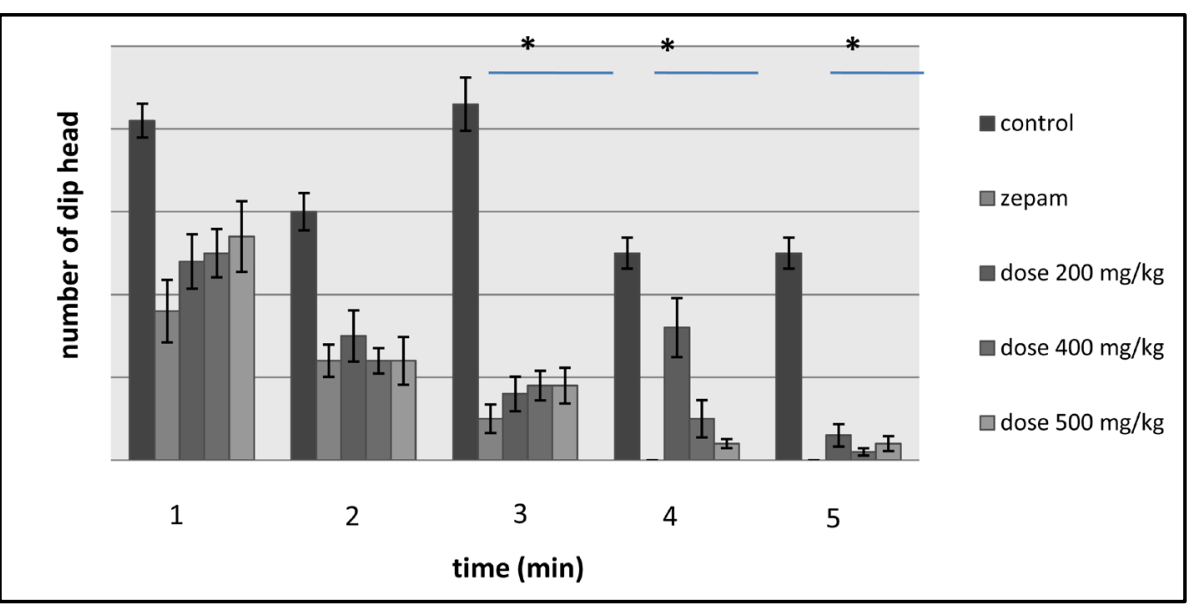

Figure 3. Illustration of the effects of Thymelaea lythroides on the exploratory activity of the lots of rats-in each minute-during the Hole Board test.

ploratory activity-the fourth minute has witnessed a significant deviation between the control group on one hand and the zepam lot and the lot tested with the dose of $500 \mathrm{mg} / \mathrm{kg}$ of $T$. lythroides's extract on the other hand, while there was no significant variation between the control lot and the groups that have received the doses of 200 and $400 \mathrm{mg} / \mathrm{kg}$. Then last but not least, during the fifth minute of the test, there was a decrease in the activities of the groups of rats that have received the doses of $200 \mathrm{and} 400 \mathrm{mg} / \mathrm{kg}$, while-similarly to in the fourth minute-the lots treated with zepam showed no signs of activity and the lot of control and the lot tested with the $500 \mathrm{mg} / \mathrm{kg}$ dose kept the same activity level.

In comparison to the group of control which has shown higher activity, the number of head dips was lower in each of the groups tested using the doses of the Tl's extract and Zepam, and therefore, the difference was highly significant between the control lot and the other tested lots (Figure 4).

\subsubsection{Open Field Test}

The open field test's outcomes have shown a highly significant difference between the control lot and the other lots while the lot administered with Zepam and the ones tested using doses of the extract of $T$. lythroides had no significant difference in their end results (Figure 5).

The results of the square's periphery visits have shown that there was no significant difference between all the groups (i.e. the control lot, the lot tested using Zepam and the lots tested using T. lythroides).

The results on the number of discoveries have shown that there was a significant difference between the control lot and the other tested groups, while there was no difference observed between the lots receiving Zepam and the groups treated using the T. lythroides's extract doses (Figure 6). The effects of the treatments on locomotors' activity were measured during a 10 minute period using locomotors' activity apparatus, and it was discovered that the locomotors' activity decreased for the rats administered with the $T l$ extract at doses of 200, 400 and $500 \mathrm{mg} / \mathrm{kg}$ when compared with the control lot that has received table oil and the group treated by Zepam, and these changes were statistically significant (Figure 7).

\section{Discussion}

Preliminary phytochemical analysis carried out during this study revealed the presence of alkaloids, tannins gallic and cathechic, heterosides, terpenoids, flavonoids, anthraquinones, sesquiterpens and saponins in $T$. lythroides. These components may exert their functions in a similar way to elements such as endogenous metabolites, ligands, hormones, signal transduction molecules and neurotransmitters, and thus, they have beneficial medicinal effects on humans due to similarities in their potential target sites (e.g. CNS, endocrine system and so on). Therefore, in order to assess the acute toxicity, ethylic extract of the plant was selected for the experiment as it contains volatile components such as the pinenes, the $\alpha$-copaene, the geranylacetone and the sesquiterpenes and beta caryophellene [4]. Furthermore, according to the OECD, if mortality was observed in a group of 5 animals then the dose administered should be considered as a toxic dose, and if mortality was observed in one ani- 


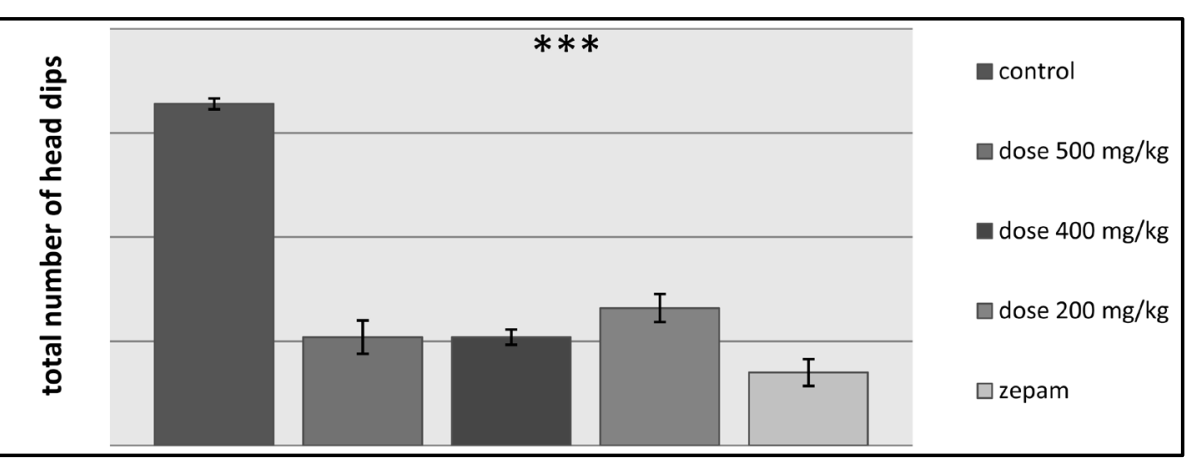

Figure 4. Representation of the results on the effects of Thymelaea lythroides on exploration and a summary of the total exploratory activity of the groups of rats during the Hole Board test.

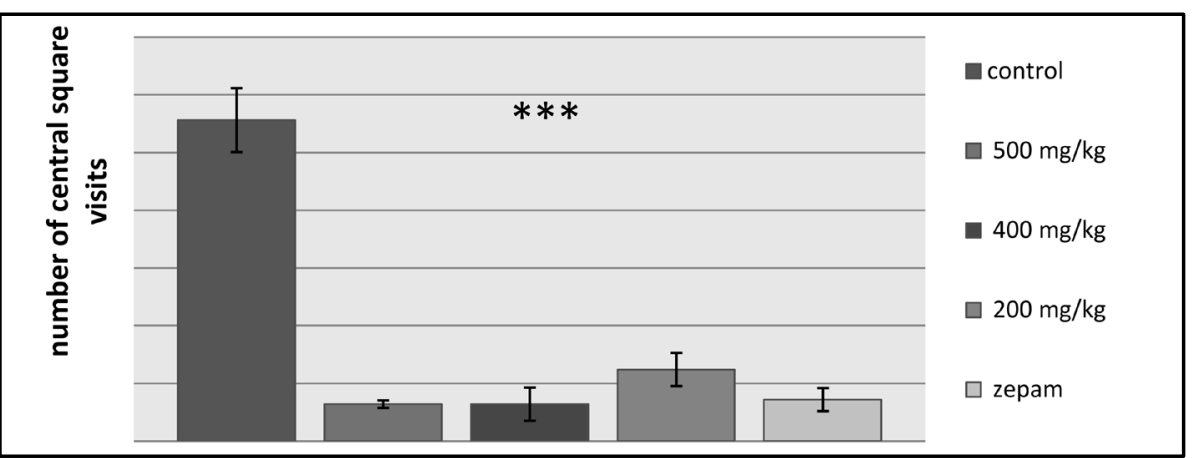

Figure 5. Effects of Thymelaea lythroides on the number of central square visits made by the lots of rats during the open field test.

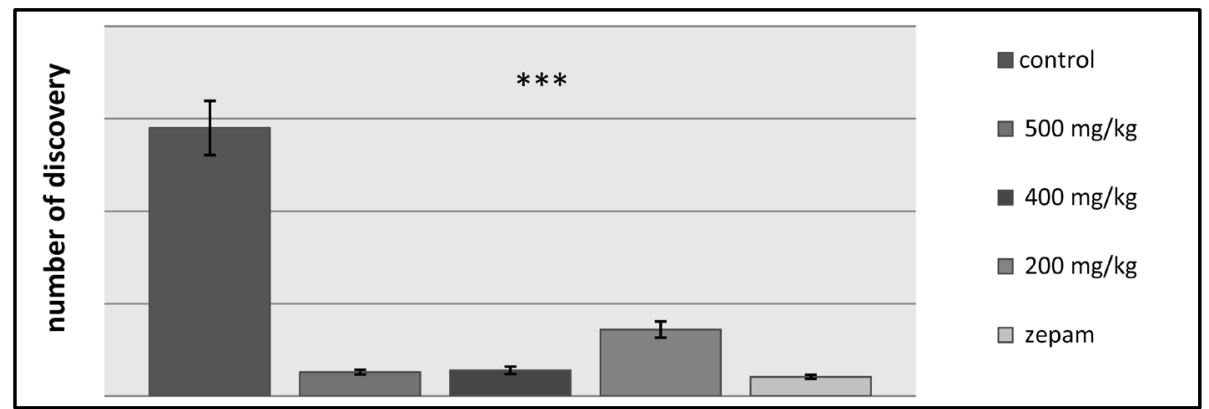

Figure 6. Representation of the effects of Thymelaea lythroides on the number of recoveries made by the rats during the open field test.

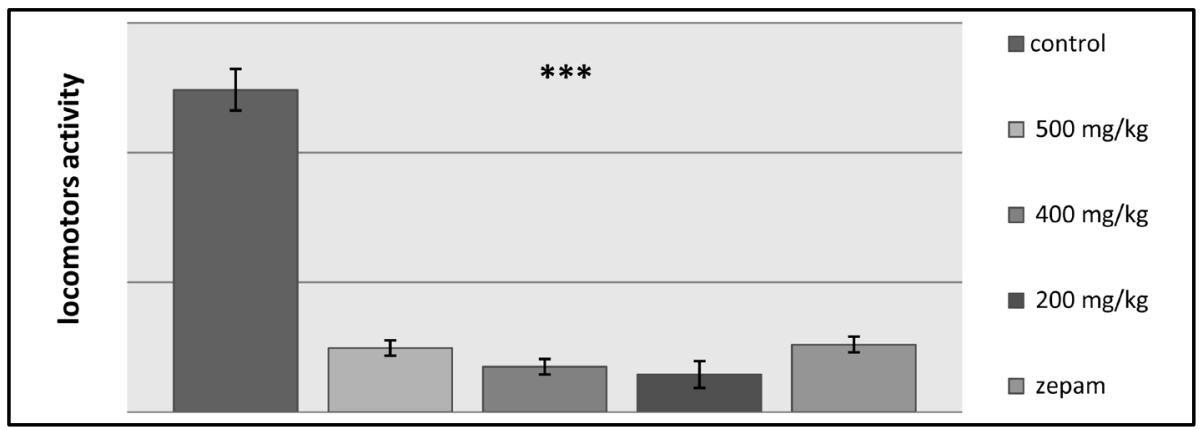

Figure 7. Illustration of the effects of Zepam, table oil and the different doses of T.lythroides on the spontaneous locomotors activity of the rats during a total period of 10 minutes. 
mal, then the same dose is repeated in order to confirm that the dose is lethal, and if there was no mortality observed, the procedure is repeated for further higher doses. However, in order to maintain the wellbeing of the animals, the OECD does not recommend the use of the $5000 \mathrm{mg} / \mathrm{kg}$ dose, and it only suggests its application under special conditions. With regard to the popularity Thymelaea preparations, it was felt appropriate to test the higher dose to identify the toxicity this animals did not show any symptoms of toxicity or signs of behavioural changes neither during the first 72 hours of the test nor later on throughout the 14 days of experiment.

Additionally, the LD50 of the extract was found to be more than $5000 \mathrm{mg} / \mathrm{kg}$, although in this dose some toxic signs were observed including: disassociation of the rats, the rats reacting little against the sonority-driven stress, sneezing, rough hair, hair loss around the eyes and physical illness. Therefore, it was confirmed that the LD50 is the dose more than $5000 \mathrm{mg} / \mathrm{kg}$ and that the NOAEL dose is $500 \mathrm{mg} / \mathrm{kg}$.

The sedative effect observed when testing the extract on the lots of rats is probably due to the presence of flavonoids, alkaloids and terpenoids in the plant. These chemical constituents have been reported to be responsible for sedative effects observed in different plant extracts [12]-[14].

Furthermore, in this study, two psychotropic tests were performed, which are the Hole Board test and the Open Field test. On one hand, the Hole Board test was used to measure the degree of exploration behavior of the tested rats, and the results of this test showed that-in comparison to the control lot-the number of head dips was lower in each of the groups tested using the doses of the T. lythroides extract and Zepam, consequently, the extract caused a reduced exploratory behavior of the rats, which is suggesting that the plant extract might be acting as a mild neurosedative agent. On the other hand, during the Open Field test, the majority of the results showed that there was a significant difference between the control lot and the other tested groups, while there was no difference observed between the lot receiving Zepam and the groups treated using the extract. The ethylic extract reduced the rats' discovery level during the open field test, which is further confirming the results obtained with the hole board test where the extract reduced the exploratory behavior of the rats. Other results of the open field test indicate that-contrary to the control group-there was a highly reduced locomotors activity within the groups treated with the extract and Zepam effects.

\section{Conclusion}

The results obtained in this study suggest that the ethylic extract of $T l$ possesses low toxicity and sedative properties. It can cause a decrease in exploratory activity and locomotion. Such effects are usually mediated by an activity in the nervous system.

\section{References}

[1] Fennane, M., Ibn Tattou, M., Raimondo, F.M. and Valdes, B. (1998) Catalogue des plantes vasculaires rares, menacees ou endemiques du maroc. Edited by francesco m. Raimondo, benito valdés, palermo: Published under the Auspices of Optima by the Herbarium Mediterraneum Panormitanum "Bocconea”, 8, 243.

[2] Métro, A. and Sauvage, C. (1955) Flore des vegetaux ligneux de la mamora. Edit. La Nature Au Maroc. Rabat. 380381.

[3] Ganiere, S. (1964) Etude anatomique des Thymelaea du Maroc. Cahiers De La Fac. Des Sciences De L’universite Med V. Serie De Biologie Vegetale. Rabat.

[4] Dohou, N., Yamni, K., Idrissi Hassani, L.M. and Gmira, N. (2004) Etude de polyphénols des feuilles d'une endémique ibéro marocaine, Tl. Acta Botanica Malacitana, 29, 233-239.

[5] Dohou, N., Yamni, K., Tahrouch, S., Idrissi Hassani, L.M., Badoc, A. and Gmira, N. (2003) Screening phytochimique d'une endémique ibéro-marocaine, Tl. Pharm. Bordeaux, 142, 61-78.

[6] Brooks, G.E. and Evans, F.J. (1990) Toxic Hazards of Plants from the Families Euphorbiaceae and Thymelaeaceae. In: Rizk, A.M., Ed., Posionous Plant Contamination of Edible Plants, CRC Press, Boca Raton, 27-63.

[7] OCDE (2000) Guidance Document on the Recognition, Assessment and Use of Clinical Signs as Humane Endpoints for Experimental Animals Used in Safety Evaluation Environmental Health and Safety Monograph Series on Testing and Assessment.

[8] CCPA (1993) Conseil canadien de protection des animaux, Manuel Sur Le Soin Et L’utilisation Des Animaux D’experimentation. Ottawa, 1, 232-256.

[9] OCDE (2001) Guidance Document on Acute Oral Toxicity. Environmental Health and Safety Monograph Series on Testing and Assessment. 24. 
[10] Dhara, A., Pal, S. and Nag Chaudhuri, A.K. (2002) Psychopharmacological Studies on Tragia Involucrate Root Extract. Phytotherapy Research, 16, 326-330. http://dx.doi.org/10.1002/ptr.891

[11] Royce, J.R. (1977) On the Construct Vality of Open Filed Measures. Psychological Bulletin, 84, 1098-1106. http://dx.doi.org/10.1037/0033-2909.84.6.1098

[12] Houghton (1999) The Scientific Basis for the Reputed Activity of Valerian. Journal of Pharmacy and Pharmacology, 51, 505-512.

[13] Dhawan, K., Kumar, S. and Sharma, A. (2001) Anti-Anxiety Studies on Extracts of Passiflora Incarnata Linneaus. Journal of Ethnopharmacology, 78, 165-170. http://dx.doi.org/10.1016/S0378-8741(01)00339-7

[14] Carlini, R. (2003) Plants and the Central Nervous System. Pharmacology, Biochemistry and Behavior, 75, 501-512. http://dx.doi.org/10.1016/S0091-3057(03)00112-6 